\title{
PROCEDIMENTO SUMARÍSSIMO: NECESSIDADE DE SUA REFORMULAÇĀO.*
}

\section{SÁLVIO DE FIGUEIREDO TEIXEIRA * *}

Há cinco (5) anos, em conferência proferida nesta Capital, no "Ciclo de Palestras de Direito Processual Civil", promovido pelo Departamento de Direito Civil e Processual Civil da Universidade Federal do Paraná, o Prof. Calmon de Passos dava início ao seu pronunciamento enfatizando que, àquela altura, parecia ter chegado o momento de mudar o centro de interesse das pesquisas e reflexões dos estudiosos, deslocando-o da tarefa exegética, sem dúvida a prioritária num primeiro momento, para a tentativa de compreensão sistemática e unitária do novo diploma processual, parecendo-Ihe, ainda, inadiável a análise e avaliação da jurisprudência já produzida após a vigência do Código.

Dessa observação, que se encontra na prestigiosa "Revista da Associação dos Magistrados do Paraná", 14/17, permito-me extrair, dentre outras, duas ilações, para trazê-las, neste in ício, à reflexão dos participantes deste "Ciclo de Estudos".

A primeira, para registrar uma vez mais o pioneirismo da gente desta terra na interpretação, na compreensão e na iniciativa de aprimoramento da nossa lei instrumental codificada, registro que seria dispensável em face das repercussões que tiveram os conclaves aqui realizados, com especial destaque para o "Simpósio", de 1975, e o "10. Encontro Nacional de Processo Civil", de 1980, sem dúvida os dois eventos de maior projeção ocorridos após a entrada em vigor do atual Código de Processo Civil e que também serviram para confirmar a organização exemplar e a fidalguia da hospitalidade deste acolhedor e bravo povo paranaense.

Como segunda ilação, sobreleva anotar que, se a preocupação exegética dominou os primeiros momentos de vigência do Código, e se, cinco anos após, se mostrava recomendável a

\footnotetext{
(•). Conferência pronunciada no Ciclo de Estudos de Processo Civil, realizada no Salão Nobre da Fac. de Direito da UFPr no dia 12 de agosto de 1983, sob o patrocínio da OAB-Pr. e AMP.

(•) Juiz do TAMG e Professor na UFMG
} 
mudança de rumo das investigações doutrinárias, agora, decorridos dez (10) anos, a bússola está a indicar um novo horizonte, no qual a primazia deve ser com o aperfeiçoamento do texto legal e o próprio sistema, sem com isso desprezar-se o anseio de uniformizar a interpretação ou, pelo menos, de reduzir ao mínimo os pontos de divergência, haja vista que, como já se afirmou, não se pode ter como ideal a Justiça que se mostra vacilante, indecisa, sobretudo porque, perante doutrina e jurisprudência incertas, ninguém está seguro do seu direito.

Notórias, e com graves repercussões sociais, se apresentam as deficiências da tutela jurisdicional, quer pela dificuldade de acesso ao Judiciário, quer pela morosidade na sua entrega, para não dizermos da sua baixa qualidade em muitos casos.

Tais deficiências, como cediço, originam-se fundamentalmente em dois polos, a saber, nas organizações judiciárias ultrapassadas, e sem recursos, e na inadequada legislação.

Não se põe em dúvida que as carências mais significativas residem, entre nós, no âmbito da organização judiciária, via de regra desprovida das conquistas da moderna tecnologia e dos recursos indispensáveis a um Poder que se afirma independente mas que sequer dispõe de autonomia administrativa e financeira.

Se assim ocorre em relação à organização judiciária e, infelizmente, não se descortinam nos horizontes oficiais perspectivas alentadoras e dignas de entusiasmo, por outro lado não se pode deixar de reconhecer que, embora injusta a ótica dos que atribuem ao Direito Processual a responsabilidade pelas mazelas forenses, não menos certo é que não contamos com uma legislação afinada com os reclamos da sociedade atual e do homem que esta integra, que deveriam ser, em um Estado que se diz democrático, os destinatários das preocupações governamentais, pois é a eles que lhe incumbe, dentro dos princípios constitucionais, dar segurança, paz e bem estar.

É induvidoso, convenhamos, que os cientistas do Direito normalmente se ocupam da construção e da compreensão do universo jurídico, buscando dar aos sistemas jurídicos a harmonia e a coerência de que estes necessitam, quando então, prioritariamente, e com razão, se voltam para a teoria geral do Direito, na qual todos encontramos respostas para as nossas inquietações e incertezas de maior profundidade.

Em face de tal postura, no entanto, não se pode perder de vista a corajosa advertência de Cappelletti ("Giustizia e società", Milão, 1977) segundo a qual muitos processualistas gastam o seu 
tempo e sua energia no exame de problemas abstratos e dogmáticos, que servem à elaboração de livros, mas nem sempre conduzem à compreensão e ao aperfeiçoamento do fenômeno social do processo. Mesmo porque, aduza-se, a própria compreensão dos conceitos deve ser voltada para a realização prática do Direito, a saber, para a consecução do bem comum e da paz social. Daí a eterna atualidade da lição de Carnelutti, na introdução do seu monumental "Sistema", ao dizer que não somente aquela obra, mas toda a sua produção científica, se assentara em três idéias capitais, que contemplam a realidade, a instrumentalidade e a unidade do Direito.

Neste quadro, ao jurista cabe não apenas compreender e interpretar o sistema legal vigente e contribuir para a evolução do pensamento científico, mas igualmente contribuir para a realização prática do Direito, inclusive participando da elaboração das normas e das alterações que se mostrarem imprescindíveis ao aprimoramento da ordem jurídica. Como acentuou Ripert, no preâmbulo de "O regime democrático e o Direito Civil moderno", Saraiva, 1937, ao propugnar maior participação do jurista na formulação da ordem jurídica, "preocupando-se exclusivamente com a técnica, o jurista renuncia a dirigir, a criar o direito". E, citando Hauriou, acrescentou o mestre francês que "reduzir o direito a uma técnica é rebaixá-lo".

Partindo-se da premissa de que não dispomos de uma legislação processual coerente com a nossa realidade, verifica-se de início que as suas deficiências se situam particularmente nos procedimentos, que se mostram, muitas vezes, excessivamente formalistas e divorciados da multifária gama de peculiaridades ensejadas pela nossa geografia continental e, em especial, distanciados das diversidades sócio-econômicas do nosso país.

Nesta perspectiva, não seria demasiado repetir que parte alguma do diploma processual está a reclamar mais atenção do legislador do que o procedimento que o Código impropriamente rotulou de "sumaríssimo", conclusão a que parece também ter chegado o "10. Encontro Nacional de Processo Civil", tanto assim que veio a destacar a sua apreciação como enfoque prioritário, senão único, do anunciado "20. Encontro", cuja realização, infelizmente, se vem frustrando.

A par de simplificações nos procedimentos especiais e no ordinário, e sem prejuízo da adoção de outros procedimentos sumários (dentre os quais, verbi gratia, o monitório) que se mostrarem recomendáveis, está o sumaríssimo atual a reclamar prioridade, tamanho o descompasso entre o objetivo com que 
foi criado e a sua aplicação no foro, o que lhe tem merecido irônicas designações de "o mais ordinário de todos" e "o ordinaríssimo".

Seus pontos críticos são já bastante conhecidos e divulgados, razão pela qual dispenso-me de aqui novamente relacionálos. A título de colaboração e com o objetivo maior de suscitar o interesse na sua reformulação, ouso apresentar a sugestão que se segue, em forma de esboço, com os fundamentos ora expostos.

Em primeiro plano, não se afigura vantajosa a simples supressão do atual sumaríssimo, uma vez que o mesmo, com meIhor disciplina, poderá produzir resultados amplamente satisfatórios, como atestam a nossa tradição legislativa e o direito comparado.

Em segundo lugar, não se apresenta incompatível o sumaríssimo com a eventual adoção de outros procedimentos que se pretenda céleres, sendo certo que, no tocante ao anunciado procedimento do chamado "Juizado das Pequenas Causas", à parte autora caberá optar pelo ajuizamento da sua pretensão no âmbito da competência deste ou perante o juízo comum ("Revista da Amagis", vol. 1/149).

Em terceiro lugar, recomendável se apresenta, a exemplo do que concluiu, a título de sugestão, o “10. Encontro Nacional de Processo Civil" ("Revista do Instituto dos Advogados do Paraná", ed. 1980, p. 529), que se desmembre o atual sumaríssimo, levando-se em conta que algumas pretensões podem ser amparadas por procedimento consideravelmente simplificado.

Em quarto lugar, acertada essa subdivisão, cumpre dar a cada um dos procedimentos desdobrados um elenco de causas correspondentes às suas características e à natureza das respectivas pretensões.

Em quinto lugar, dadas as dimensões territoriais do nosso país e a sua complexa diversidade, recomenda-se que seja facultado aos Estados-membros legislar supletivamente em matéria procedimental, como sugeriu a Associação dos Magistrados Brasileiros (anais do VIII Congresso dos Magistrados Brasileiros", Manaus, 1980). Essa inovação, contudo, como se sabe, dependerá de alteração a nível constitucional.

Em sexto lugar, impõe-se reconhecer que, nos procedimentos mais simplificados, maior realce deve ter a tentativa de conciliação, motivo pelo qual deve a mesma ocorrer ainda na fase inicial, e não apenas quando da audiência de instrução e julgamento, como atualmente se verifica.

Em sétimo lugar, cumpre atentar para o fato de que um 
dos fatores que mais concorrem para a inobservância da desejada solução rápida dos litígios reside no congestionamento das pautas de audiência nos centros mais populosos, merecendo registro a esdrúxula circunstância de que a atual necessidade de audiência de instrução e julgamento inviabiliza até mesmo a melhor das inovações do Código de 1973, que é o julgamento antecipado da lide.

Em oitavo lugar, não se pode deixar de anotar que não se mostra conveniente a liberalização da intervenção de terceiros em causas sob procedimento sumaríssimo, pelas conseqüências práticas que conhecemos todos nós que militamos no dia-a-dia do foro.

Em nono lugar, a experiência tem demonstrado que não é a simples redução dos prazos que torna um procedimento mais rápido e menos complexo, mas sim a adoção de determinadas variantes.

Em décimo lugar, cumpre também assinalar que a adoção das medidas aconselháveis ao eficaz funcionamento dos procedimentos sumário e sumar íssimo não pode prescindir dos princípios que norteiam o "due process of law".

\section{ESBOÇO A TITTULO DE SUGESTĀO}

Art. 10. ) Capítulo III do...

Capítulo III

Dos procedimentos sumário e sumaríssimo.

Art. 275. Observar-se-á o procedimento sumário:

II - nas causas cujo valor não exceder vinte (20) vezes o maior salário mínimo vigente à época do ajuizamento da demanda;

II - nas causas, qualquer que seja o valor:

a) que versem sobre a posse ou direitos reais relativos a móveis e semoventes;

b) de arrendamento rural e de parceria agrícola;

c) que tenham por fundamento prescrições de convenção de condomínio, ressalvados os casos sujeitos à via executiva;

d) de indenização por danos decorrentes de acidente de veículo de via terrestre;

e) de cobrança de seguro obrigatório;

f) de cobrança de honorários dos profissionais liberais, ressalvado o disposto em legislação especial.

Parágrafo único - Esse procedimento não será observado nas ações relativas ao estado e à capacidade das pessoas. 
Art. 276. Na petição inicial (arts. 282 e 283) o autor apresentará o rol de testemunhas e, se requerer, formulará os quesitos e poderá apresentar assistente técnico.

§ 10. - O juiz determinará a citação do réu para responder no prazo de dez (10) dias, designando, no mesmo despacho, data para a audiência de instrução e julgamento:

§ 20. - Com a contestação, o réu apresentará seu rol de testemunhas e, em caso de perícia, formulará quesitos e poderá indicar assistente técnico.

§ 30. - A impugnação ao valor da causa (art. 261), bem como as exceções (art. 304), serão argu ídas na contestação.

Art. 277. Ocorrendo qualquer das hipóteses dos arts. 329 e 330 , será proferida sentença em julgamento conforme o estado do processo.

Art. 278. Não sendo caso de julgamento antecipado, a sentença será proferida em audiência, logo que encerrados os debates orais, ou no prazo de dez (10) dias.

$\S 10$. - Antes de iniciada a instrução o juiz tentará conciliar as partes. (art. 448).

§ 20. - Deverá o juízo, sempre que possível, designar data apenas para fins de conciliação, se as partes tiverem domicílio ou residência na mesma comarca ou em comarcas próximas. A convocação, para esse fim, será por via postal, em mãos próprias, com a advertência de que, não comparecendo o réu, os fatos apontadios na inicial serão tidos como verdadeiros.

Art. 279. No procedimento sumário não cabe ação declaratória incidental, oposição e chamamento ao processo. 0 agravo somente poderá ser interposto em sua forma retida e a sentença deverá ser proferida dentro do prazo de cento e vinte (120) dias, a contar da propositura da ação.

Art. 280. O procedimento sumaríssimo poderá ser adotado nas ações de cobrança ou de indenização, cujo valor não exceder dez (10) vezes o maior salário mínimo vigente à época do ajuizamento da demanda.

$\S 10$. - Somente é adimissível o procedimento sumaríssimo entre partes residentes em lugar certo, capazes de transigir, e quando formulado pedido líquido. 
$\S 20$. - As partes comparecerão a juízo acompanhadas das testemunhas, e apresentando os documentos relativos à lide. Após ouvidos os litigantes, promoverá o juiz a tentativa de conciliatária. Não obtida a conciliação, o juiz inquirirá as testemunhas sobre os pontos essenciais da lide, apreciará os documentos e proferirá de imediato a sentença. Os depoimentos serão colhidos sem maior formalidade.

§ 30. - Comparecendo a juízo apenas o autor, a petição será apresentada por escrito, em duas (2) dias, ou formulada verbalmente, devendo o serventuário, nessa segunda hipótese, tomá-la por termo. Na mesma oportunidade, será designada data para a audiência, com imediata intimação do demandante e expedição de carta citatória do demandado (art. 223), registrada e para entrega em mãos próprias. A citação por mandado será utilizada apnas em caráter supletivo.

§ 4 ? - Não comparecendo o autor à audiência, será extinto o processo sem julgamento do mérito. Não comparecendo o réu, os fatos apontados pelo autor na inicial serão tidos como verdadeiros (art. 319).

$\S 50$. - O termo da audiência consignará a identificação das partes, anotará os pontos fundamentais do pedido e da resposta, resumirá as informações prestadas pelas testemunhas e conterá, por extenso, a sentença.

§60. - As decisões interlocutórias somente poderão ser impugnadas por agravo retido.

$\S 70$. - 0 juiz poderá julgar inadequado o procedimento sumaríssimo, como nos casos em que considere imprescindível a prova pericial processada em juízo ou a expedição de precatória. Desse julgamento não cabe recurso.

$\S 8^{\circ}$. - Nas causas sob procedimento sumaríssimo, a sentença deve ser proferida no prazo de trinta (30) dias, isentas tais causas de quaisquer despesas.

§90. - As leis de organização judiciária poderão estabelecer órgãos especiais para o julgamento dos recursos interpostos nas causas sob este procedimento.

$\S 10$ - Não cabe, neste procedimento, a declaratória incidental, a reconvenção, a oposição e a intervenção de terceiros.

Art. 281. Nas causas sob procedimento sumário ou sumaríssimo, podem as partes, por opção manifestada na inicial e na contestação, ou por ambas formulada no in ício da audiência, autorizar o juiz julgar por equidade, fora das regras e formas de direito, caso em que a sentença não fica sujeita a recurso, salvo se o contrário convencionarem as partes. 
Parágrafo único - 0 julgamento por equidade não dispensa o juiz de fundamentar sua decisão.

Art. 20. Fica revogado o $§ 2^{\circ}$. do art. 315 , passando o atual $\S 10$. a ser parágrafo único.

Art. 30. Ao art. 530 é acrescentado o seguinte parágrafo: “Parágrafo único. Não são admissíveis embargos infringentes nas ações sob procedimento sumaríssimo.

Art. 40. A expressão "procedimento sumaríssimo" fica substituída por "procedimento sumário ou sumaríssimo" nos arts. 273, 550 e 551, § $3^{\circ}$. do Código de Processo Civil e as referências ao procedimento sumaríssimo, contidas em leis especiais, são transformadas em referências ao procedimento sumário.

Art. 50. Revogam-se as disposições em contrário.

Procedimento sumaríssimo. Questões controvertidas.

\section{Proposições}

1. Conclusões aprovadas por unanimidade no "VI Encontro Nacional dos Tribunais de Alçada", Belo Horizonte, junho, 1983:

a) "Nas causas sob procedimento sumaríssimo, tem curso nas férias o prazo recursal".

b) "O procedimento não fica à escolha da parte, devendo o juiz determinar a conversão quando possível. Contudo, em se tratando de causa na qual o procedimento sumaríssimo seria o adequado, não se deve decretar a nulidade se foi observado o procedimento ordinário (CPC, arts. 244 e 250, parágrafo)".

c) "Nas causas sob procedimento sumaríssımo há preclusão se o autor não arrola suas testemunhas quando do ajuizamento da causa".

2. Conclusão aprovada por maioria no referido "Encontro":

a) "No procedimento sumaríssimo não é viável a declaratória incidente".

3. 0 procedimento sumaríssimo a que se refere o art. 110, $\S 4^{\circ}$., da Lei no. 6.015/73 (Lei dos Registros Públicos) não é o disciplinado no CPC, uma vez que ali se trata de jurisdição voluntária.

4. É possível a concessão de liminar nas possessórias mobiliárias de força nova.

5. O prazo de dez (10) dias para a realização da audiência somente se conta após à juntada do mandado ou da precatória aos autos.

6. No sumaríssimo, pode o juiz desdobrar a audiência em duas, 
destinando-se a primeira a tentativa de conciliação e, não havendo acordo, ao recebimento de defesa e prova que não a testemunhal, a exemplo da praxe trabalhista. Do mandado, entretanto, tais circunstâncias deverão constar.

7. Nada-impede, sendo mesmo aconselhável, que, no sumaríssimo, eventual exceção processual seja apresentada e apreciada antes da audiência. $\mathrm{O}$ mesmo se pode afirmar também em relação ao incidente de impugnação ao valor da causa.

8. A cobrança de honorários advocat ícios somente pode verificarse pela via executiva desde que no contrato escrito (Lei no. $4.215 / 63$, art. 100 , parágrafo único) haja valor estabelecido (CPC, art. 586), uma vez que a ação executiva mencionada na citada lei e a do CPC anterior.

9. Os recursos interpostos contra as sentenças proferidas nos processos de que trata o art. 107 do "Estatuto da Terra" têm efeito também suspensivo.

10. O qualificativo "municipais", da letra " $g$ ", do inciso II, do art. 275, CPC, somente se refere a posturas.

11. A Lei no. 6.205/75 (s/"valor de referência") se aplica ao procedimento sumaríssimo.

12. A via executiva não é hábil para a cobrança, pelo síndico, de quota de participação dos condomínios nos encargos (tributos e despesas) do condomínio.

13. Em se tratando de imóvel urbano loteado, o promitente comprador, munido do contrato formalizado, não precisará da ação de adjudiçação compulsória mencionada no art. 10. da Lei no. 6.014. O mesmo, entretanto, não se dá em relação ao imóvel não-loteado, haja vista que, no tocante a este, se aplica o citado dispositivo legal, vigente ainda o art. 22 do DL no. 58/37. 